\title{
Albuquerque Convention Center
}

UPPER LEVEL
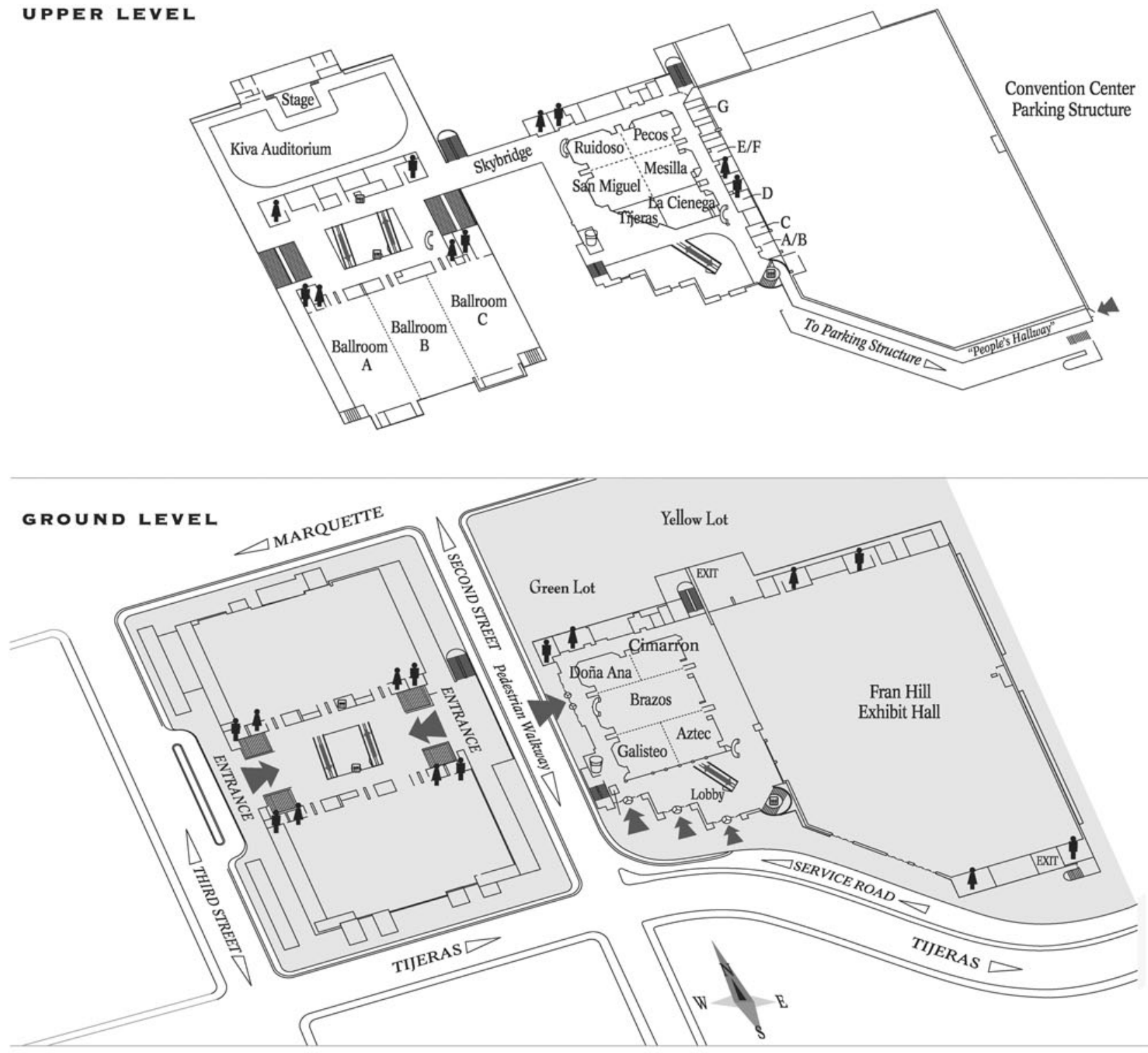

\section{LOWER LEVEL}

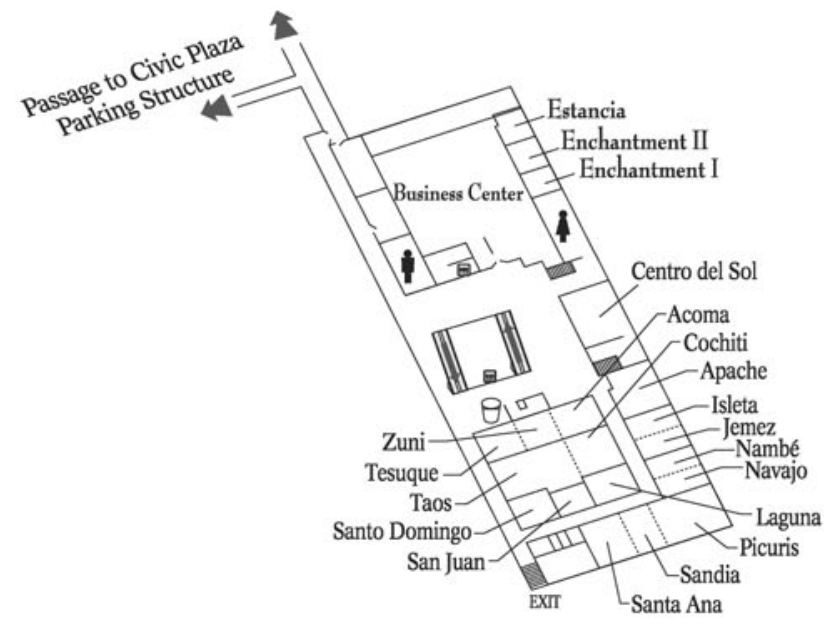

\section{LEGEND}

$\rightarrow$ Pedestrian Entrance m Elevator

- Men's Restroom Escalator

4 Women's Restroom Stairs

$\theta$ Vending

$\zeta$ Courtesy Phones \& All areas of the Albuquerque Convention Center are accessible to people with mobility impairments 